\title{
Comportamento de Ovinos em Sistema Silvipastoril com Cajueiro ${ }^{1}$
}

Marcônio Martins Rodrigues², Maurílio Souza dos Santos², Tania Maria Leal ${ }^{3}$, Maria Elizabete de Oliveira ${ }^{4}$, Raniel Lustosa de Moura ${ }^{2}$, Daniel Louçana da Costa Araújo ${ }^{2}$, Francelino Neiva Rodrigues ${ }^{5}$, Joelton Ibiapina de Vasconcelos ${ }^{6}$

Resumo: Avaliou-se o comportamento de ovinos Santa Inês na fase de terminação em sistema silvipastoril de capim-massai com cajueiro com ou sem estilosantes Campo Grande. Foi avaliada a massa de forragem, estrutura do pasto e os tempos de pastejo, ruminação, ócio, deslocamento, taxa de bocado dos animais e a frequência com que cada espécie foi pastejada. Apesar da maior massa de forragem total no pasto com estilosantes, massa de folhas verdes, incluindo a leguminosa, não diferiu entre os tratamentos. A presença da leguminosa modificou a estrutura do dossel, com elevação da altura e da proporção de colmo. O tempo de pastejo e a taxa de bocado não diferiram entre os tratamentos, uma vez que a oferta de folhas verdes foi semelhante entre os tratamentos (6,32\% do PV). Apesar de no pasto com estilosantes a leguminosa contribuir com $23,43 \%$ da composição botânica, a reduzida relação folha:haste $(0,37)$ não foi suficiente para influenciar no comportamento dos animais. Em sistema silvipastortil com cajueiro, apesar de provocar modificações na estrutura do capim-massai, a presença de estilosantes Campo Grande em 23\% do pasto não é suficiente para modificar o comportamento de pastejo de ovinos em terminação.

Palavras-chave: estrutura, estilosantes, massa de forragem, taxa de bocado, tempo de pastejo

\section{Behavior in Sheep Silvopastoral System with Cashew}

\begin{abstract}
The Santa Inês sheep in the finishing phase behavior was evaluatedin silvopastoral system of massai grass with cashew with or without stylosanthes Campo Grande.We evaluated the herbage mass, sward structure, and grazing time, ruminating, idle shift, the bit rate of the animals and the frequency with which each species was grazed. Despite greater total forage massin the pasture with stylosanthes, mass of green leaves, including legumes, did not differ between treatments. The presence of legumes modified the canopy structure, with increased height and proportion of stem. The grazing time and bite rate did not differ between treatments, since the supply of green leaves was similar between treatment s $(6.32 \%$ of $\mathrm{BW})$. While in the pasture with the legume stylosanthes contribute $23.43 \%$ of the botanical composition, reduced leaf: stem ratio (0.37) was not sufficient to influence the behavior of animals. In silvopastoral system with cashew, although cause changes in the structure of massai grass, the presence of stylosanthes Campo Grande in $23 \%$ of the pasture is not sufficient to modify the behavior of grazing sheep intermination.
\end{abstract}

Key words: structure, stylosanthes, forage mass, bit rate, grazing time

\footnotetext{
${ }^{1}$ Parte da Tese de doutorado do segundo autor

${ }^{2}$ Doutorandodo Programa de Pós-Graduação em Ciência Animal -UFPI. e-mail: marnunes07@yahoo.com.br

${ }^{3}$ Pesquisadora da Embrapa Meio- Norte

${ }^{4}$ Departamento de Zootecnia CCA $\backslash U F P I$

${ }^{5}$ Discente do curso de Medicina Veterinária CCA\UFPI

${ }^{6}$ Discente do curso de Agronomia CCA IUFPI
} 


\section{Introdução}

Os sistemas silvipastoris (SSP) são associações de espécies florestais com plantas forrageiras herbáceas ou rasteiras e animais herbívoros que buscam a sustentabilidade de pastagens naturais e cultivadas, além de obter múltiplos produtos vegetais e animais. A implantação desse sistema deve ser benéfica para o Estado do Piauí, que possui solos predominantemente de baixa fertilidade que podem ter suas características físicas e químicas melhoradas pela ciclagem de nutrientes proporcionada pelas árvores. Essa melhoria pode ser potencializada pela utilização de leguminosas. Outra vantagem seria a formação de um microclima mais agradável para os animais, o que pode ter conseqüências positivas sobre o desempenho animal, e a maior retenção de água no solo, reduzindo assim a sazon'alidade na produção de forragem. Desse modo, o objetivo deste trabalho foi avaliar o comportamento de ovinos na fase de terminação em sistema silvipastoril com cajueiro, consorciado ou não com estilosantes Campo Grande.

\section{Material e Métodos}

O experimento foi realizado nos meses de outubro e novembro de 2011 (final do período seco), em Teresina, PI, no campo experimental da Embrapa Meio-Norte $\left(5^{\circ} 06^{\prime} 18^{\prime}\right.$ S e $\left.42^{\circ} 48^{\prime} 12^{\prime \prime} \mathrm{W}\right)$. O clima é classificado como subúmido seco, megatérmico com excedente hídrico moderado no verão. O solo da área experimental foi classificado como Latossolo Amarelo, com as seguintes características químicas: $\mathrm{pH}$ em água 5,7; Ca 1,0; $\mathrm{Mg} 0,4 ; \mathrm{K} 0,18$ e $\mathrm{Al} 0,1$ $\mathrm{cmol} / \mathrm{dm}^{3} ; \mathrm{P}$ disponível $7 \mathrm{mg} / \mathrm{dm}^{3}$; e, matéria orgânica $13,5 \mathrm{mg} / \mathrm{kg}$.

Os tratamentos consistiram de dois sistemas silvipastoris com cajueiro (Anacardium occidentale) com espaçamento $7 \times 8 \mathrm{~m}$. No tratamento 1 o capim- massai será utilizado como cultura forrageira única, e no tratamento 2 o capim-massai será consorciado com estilosantes cv. Campo Grande. Foi adotado pastejo rotacionado com 3 dias de pastejo e 24 dias de descanso. A área experimental foi dividida em dois blocos, e a área de cada tratamento dentro de cada bloco foi pastejada por 6 ovinos mestiços da raça Santa Inês com PV médio de $22 \pm 0,23 \mathrm{~kg}$ totalizando 24 animais.

Foram avaliados os tempos de pastejo, ruminação, ócio e deslocamento dos animais bem como a frequência com que cada espécie foi pastejada. Essas observações foram realizadas a cada 10 minutos no período de 7 às 17 horas. A taxa de bocados foi determinada por meio da visualização de cada animal anotando-se o tempo gasto para realizar 20 bocados com o auxílio de cronômetro (Forbes e Hodgson, 1985). As observações foram realizadas às07:00; 09:00; 11:00; 13:00; 15:00 e 17:00 horas.

O delineamento estatístico utilizado foi em blocos ao acaso em parcela subdividida, com dois blocos (parcela), dois tratamentos (com e sem estilosantes) e duas repetições no tempo (subparcela). Quando detectadas diferenças, as médias foram comparadas pelo teste de SNK utilizando nível de significância de $5 \%$ para avaliação dos resultados.

\section{Resultados e Discussão}

A produção de massa total do pasto nos sistemas avaliados não diferiram, resultado que também foi observado com relação a produção de massa de folhas. Isso porque o incremento na produtividade do pasto com leguminosa se deveu a grande participação de haste $(17,06 \% \pm 0,11)$ e ao aumento na proporção de colmo (Tabela 1).

A presença de estilosantes no pasto resultou em modificação na estrutura do pasto, com elevação da altura do pasto e aumento na proporção de colmo no pasto $(\mathrm{P}<0,05)$, além disso, mesmo com a menor área 
Rev. Cient. Prod. Anim., v.14, n.1, p.1-4, 2012

Tabela 1 - Massa de forragem e composição morfológica dos pastos de capim-massai em sistema silvipastoril consorciado ou não com estilosantes Campo Grande

\begin{tabular}{cccccccc}
\hline \multirow{2}{*}{ Pasto } & MFT & MSFV $^{1}$ & Alturam entrada & Assai saída & Folhaca pim & Colmo & Morto \\
\cline { 2 - 8 } & \multicolumn{2}{c}{$(\mathrm{Kg} \mathrm{MS} / \mathrm{ha})$} & \multicolumn{2}{c}{$(\mathrm{cm})$} & \multicolumn{3}{c}{$(\%)$} \\
Massai & $1.485,05^{\mathrm{a}}$ & $1.306,28^{\mathrm{a}}$ & $63,71^{\mathrm{b}}$ & $30,69^{\mathrm{b}}$ & $89,60^{\mathrm{a}}$ & $3,50^{\mathrm{b}}$ & $6,92^{\mathrm{a}}$ \\
Massai+estilosantes & $1.855,93^{\mathrm{a}}$ & $1.291,01^{\mathrm{a}}$ & $71,01^{\mathrm{a}}$ & $39,85^{\mathrm{a}}$ & $64,50^{\mathrm{a}}$ & $5,00^{\mathrm{a}}$ & $6,50^{\mathrm{a}}$ \\
\hline
\end{tabular}

Médias seguidas pela mesma letra minúscula nas linhas não diferem entre si estatisticamente pelo teste de SNK ao nível de 5\%

${ }^{1}$ Folhas de capim-massai + folhas de estilosantes Campo Grande

Tabela 2 - Comportamento de ovinos em sistema silvipastoril com cajueiro e capim-massai consorciado ou não com Estilosantes Campo Grande

\begin{tabular}{|c|c|c|c|c|c|}
\hline \multirow{2}{*}{ Pasto } & Pastejo & Ruminação & Deslocamento & Ócio & \multirow{2}{*}{$\begin{array}{c}\text { Taxa de bocado } \\
\text { (boc/min) }\end{array}$} \\
\hline & \multicolumn{4}{|c|}{ (h) } & \\
\hline Massai & $8,41^{\mathrm{a}}$ & $0,87^{\mathrm{a}}$ & $0,17^{\mathrm{a}}$ & $0,65^{\mathrm{a}}$ & $27,50^{\mathrm{a}}$ \\
\hline Massai+Estilosantes & $8,50^{\mathrm{a}}$ & $0,98^{\mathrm{a}}$ & $0,13^{\mathrm{b}}$ & $0,64^{\mathrm{a}}$ & $27,90^{\mathrm{a}}$ \\
\hline
\end{tabular}

Médias seguidas pela mesma letra minúscula nas linhas não diferem entre si estatisticamente pelo teste de SNK ao nível de $5 \%$

para crescimento do capim no pasto consorciado, não houve diferença na massa de folhas do capim-massai $(\mathrm{P}>0,05)$ entre os tratamentos (Tabela 1). Paciolloet al. (2003) trabalhando com Brachiaria decumbensem consorcio com Stylosanthes guianensis também observaram este efeito e o atribuíram ao maior aporte de N no sistema através da leguminosa. A elevação do dossel, com alongamento do colmo pode ser atribuída ainda a competição por luz entre a gramínea e a leguminosa uma vez que essa apresentou uma altura de $71,01 \mathrm{~cm}$.

O tempo de pastejo e a taxa de bocado não foram afetados pelos tratamentos empregados (Tabela 2). O fato de ambos os tratamentos apresentarem a mesma massa de folhas verdes, resultando em oferta de folhas verdes de $6,32 \%$ do PV, considerada como não limitante por Euclides et al. (2009). Além disso, a maior altura de saída do capim-massai no pasto consorciado possibilitou em uma profundidade de pastejo semelhante $(31,37 \pm 8,1 \mathrm{~cm})$, proporcionando uma ausência do efeito da altura sobre o comportamento de pastejo. Este comportamento não foi observado por Gonçalves et al. (2009) quando observaram tempos de pastejo e taxa de bocados de ovinos diferentes com as variações da altura do dossel em pastos nativos.

Apesar de no pasto com estilosantes a leguminosa contribuir com $23,43 \%$ da composição botânica, a reduzida relação folha:haste $(0,37)$ não foi suficiente para influenciar no comportamento dos animais. Este fato pode ser confirmado pela baixa frequência com que a leguminosa foi pastejada pelos animais $(13,48 \pm 0,14 \%)$. Aroeira et al. (2005) observou que quando a proporção de estilosantes no pasto reduz para valores próximos a $20 \%$, sua participação na dieta cai para menos de $15 \%$.

Tanto no pasto com ou sem estilosantes a frequência com que os animais pastejaram as folhas do cajueiro foi baixa $(0,16 \%$ e $0,39 \%$ respectivamente), indicando que o a terminação de ovinos sob a copa de cajueiro provavelmente não tenha efeito negativo sobre a produtividade da cultura.

\section{Conclusões}

Em sistema silvipastortil com cajueiro, apesar de provocar modificações na estrutura do capim-massai, a presença de estilosantes Campo Grande em 23\% do 
pasto não é suficiente para modificar o comportamento de pastejo de ovinos em terminação.

\section{Literatura Citada}

FORBES, T.D.A.; HODGSON, J. Comparative studies of the influence of sward conditions on the ingestive behaviour of cows and sheep. Grass and Forage Science, v.40, p.69-77, 1985.

AROEIRA, L. J. M; PACIOLlO, D. S. C.; LOPES, PACIOLlO, D. S. C.; AROEIRA, L. J. M.; F. C. F.; MORENZ, M. J. F.; SALIBA, E. S.; SILVA, ALVIM, M. J.; CARVALHO, M. M. Características J. J.; DUCATTI, C. Disponibilidade, composição produtivas e qualitativas de pastagens de braquiária bromatológica e consumo de matéria seca em em monocultivo e consorciada com estilosantes. pastagem consorciada de Brachiaria decumbens com Pesquisa Agropecuária Brasileira. v. 38, n. 3, p. 421 Stylosanthes guianensis. Pesquisa Agropecuária. 426, 2003.

Brasileira, v.40, n.4, p.413-418, 2005.

GONÇALVES, E. N; CARVALHO, P. C. F; EUCliDES, V. P. B.; MACEDO, M. C. M.; VALlE, DEVICENZI, T.; CARASSAI, I. J.; BREMAN, C.; C. B.; DIFANTE, G. S.; BARBOSA, R.A.; CACERE, FISCHER, V. Relações planta-animal em ambiente E. R. Valor nutritivo da forragem e produção animal pastoril heterogêneo: processos de ingestão de em pastagens de Brachiaria brizantha. Pesquisa forragem. Revista Brasileira de Zootecnia. v. 38, n. 9, Agropecuária Brasileira, v.44, n.1, p.98-106, 2009. p. 1655- 1662, 2009. 